\title{
DIGITALCOMMONS
}

6-1-2004

\section{Spousal Congruence on Disability, Pain, and Spouse Responses to Pain}

Annmarie Cano

Wayne State University, acano@wayne.edu

Ayna B. Johansen

Wayne State University

Michael Geisser

University of Michigan - Ann Arbor

\section{Recommended Citation}

Annmarie Cano, Ayna B Johansen, Michael Geisser

Spousal congruence on disability, pain, and spouse responses to pain

Pain, Volume 109, Issue 3, June 2004, Pages 258-265

http://dx.doi.org/10.1016/j.pain.2004.01.036

Available at: http://digitalcommons.wayne.edu/psychfrp/10

This Article is brought to you for free and open access by the Psychology at DigitalCommons@WayneState. It has been accepted for inclusion in

Psychology Faculty Research Publications by an authorized administrator of DigitalCommons@WayneState. 
Pain. 2004 June ; 109(3): 258-265. doi:10.1016/j.pain.2004.01.036.

\title{
Spousal congruence on disability, pain, and spouse responses to pain
}

\author{
Annmarie Cano ${ }^{\mathrm{a},{ }^{*}, \text { Ayna B. Johansen }}{ }^{\mathrm{a}}$, and Michael Geisser ${ }^{\mathrm{b}}$ \\ aDepartment of Psychology, Wayne State University, 71 W. Warren Avenue, Detroit, MI 48202, USA \\ bDepartment of Physical Medicine and Rehabilitation, University of Michigan, Ann Arbor, MI, USA
}

\begin{abstract}
We examined congruence between chronic pain patients and their spouses on their reports of patient pain severity, patient disability, and spouse responses to pain. Patients reported that they were more physically and psychosocially disabled than their spouses reported them to be. However, spouses reported that the patients' pain was more severe than patients reported. Depressive disorders in the patient and gender interacted with patient-spouse ratings. For physical and psychosocial disability, depressed patient couples reported significantly larger differences in disability ratings than nondepressed patient couples. In addition, female patients' disability was rated as more severe by the female patients than by their husbands. Male patient couples did not report differences on physical disability. Findings relating to other forms of disability and to spouse responses are also described. The results are discussed in the context of an interpersonal perspective of chronic pain and have implications for the assessment of pain and disability.
\end{abstract}

\section{Keywords}

Chronic pain; Depression; Disability; Pain severity; Spouse responses

\section{Introduction}

Recent studies have focused on the differences between caregiver and patient ratings of illness. Caregivers consistently overestimate pain severity in cancer patients (Clipp and George, 1992; Miaskowski et al., 1997; Yeager et al., 1995) whereas some spouses overestimate and others underestimate the pain and disability of rheumatoid arthritis (RA) and osteoarthritis patients (Cremeans-Smith et al., 2003; Riemsma et al., 2000). Diagnoses of depression and gender are two variables that may affect the degree to which married couples are incongruent in their reports of patients' pain experiences.

Adapting Joiner and Coyne's (1999) premise that depression can affect interpersonal interaction, depressive social withdrawal may diminish patients' ability to communicate about pain and spouses' ability to observe pain behaviors. Spouses of depressed patients may also withdraw to protect themselves from distress (i.e. defensive distancing; Pyszcynski et al., 1995). Therefore, depressed patient couples may report more incongruence than non-depressed patient couples. Indeed, caregiver-patient incongruence on pain and disability is associated with psychological distress in patients and spouses (Cremeans-Smith et al., 2003; Miaskowski et al., 1997; Riemsma et al., 2000). Yet, it is still unknown whether incongruence is related to 
depression diagnoses. Furthermore, grouping dyads as congruent or incongruent has prevented analyses of the degree to which depression is related to incongruence.

In terms of gender, Beaupre et al. (1997) found that wives of male patients were more accurate in judging their partners' pain than husbands of female patients. However, other studies of patient-spouse congruence did not examine gender (Cremeans-Smith et al., 2003; Riemsma et al., 2000). Person perception research has demonstrated that wives are more accurate perceivers of their husbands' personality traits and non-verbal behaviors than vice versa (Bernieri et al., 1994; Hall, 1978; Ickes et al., 2000). Therefore, male patients and their wives may be more congruent than female patient couples on patients' pain and disability.

Some attention to spouse behaviors is also necessary given spouses' important role in the pain process (e.g. Fordyce, 1976; Turk et al., 1983). Spouses are motivated to maintain a good opinion about their partners to a greater extent than the partners are motivated to maintain a good opinion of themselves (Senécal et al., 2003). Thus, patients may report that their spouses engage in more supportive and fewer negative responses as compared to spouse reports of their own responses. Patient depression may enhance agreement between spouses because the patient is less motivated to perceive the relationship in a positive manner. Female patient couples may report more incongruence than male patient couples because wives of male patients may be motivated to portray themselves more positively than husbands of female patients.

In the current study, we expected that spouses would report more pain severity and disability than patients. We also expected that depressed patient and female patient couples would report more incongruence than non-depressed patient and male patient couples. Last, we explored the extent to which patients and their spouses were congruent on spouse responses to pain. These hypotheses were tested in a married chronic musculoskeletal pain sample.

\section{Method}

\subsection{Participants}

Participants were 110 patients attending a multidisciplinary pain clinic and their spouses. All patients reported chronic (i.e. at least 6 months duration) musculoskeletal back or neck pain due to a variety of problems (e.g. herniated disc, degenerative disc disease, osteoarthritis, complications from surgery). Most patients $(n=81,73.6 \%)$ also reported pain in other sites (e.g. arms, legs). A sample such as this is ideal since few published studies about patientspouse incongruence have been conducted with musculoskeletal samples (i.e. osteoarthritis; Beaupre et al., 1997; Cremeans-Smith et al., 2003).

Patients and spouses were predominantly Caucasian (patients: $88.2 \%, n=97$; spouses: $85.5 \%$, $n=94)$ and $56 \%(n=62)$ of the patients were female. Participants were married for an average 18.24 years $(\mathrm{SD}=12.12$; minimum $=6$ months; maximum $=60$ years $)$. Other patient and spouse demographics are reported in Table 1. For clarity, 'patients' refers to the chronic pain patients whereas 'spouses' refers to the pain patients' spouses.

\subsection{Measures}

2.2.1. Multidimensional pain inventory (MPI-Patient Version, Kerns et al., 1985; MPI-Spouse Version, Kerns and Rosenberg, 1995)—The 52-item MPI-Patient Version and MPI-Spouse Version assess psychosocial variables that are associated with the chronic pain experience. All subscales of the MPI have good construct and discriminant validity, internal consistency, and test-retest reliability (Kerns and Jacob, 1992; Kerns et al., 1985). The three-item pain severity subscale was used to assess current pain severity and intensity. Patients' pain was rated using 7-point Likert-type scales (e.g. $0=$ not at all severe, 6 
$=$ extremely severe). Patients and their spouses reported on the patients' pain with two of the items referring specifically to the past week or the time of study participation. In the current study, inter-item reliabilities for both patient and spouse scales were excellent (pain severity: patient, $\alpha=0.86$; spouse, $\alpha=0.84$ ). The spouse responses to pain subscales assessed negative or punishing spouse responses (4 items), solicitous or helpful spouse responses (6 items), and distracting spouse responses (4 items). Participants used a 7-point Likert-type scale to indicate the frequency with which spouses responded to the patients in a particular way (e.g. $0=$ never, $6=$ very often). Participants were not given a particular timeframe (e.g. in the last week) on which to report; however, the wording of the items assumes that the participants will report on spouse behaviors that are occurring at the time of interview or in the very recent past. Overall, the inter-item reliabilities were good for patients' reports of how their spouses responded to them (negative $\alpha=0.87$, solicitous $\alpha=0.78$; distracting $\alpha=0.70$ ) and for spouses' reports of how they responded to the patients' pain (negative $\alpha=0.76$; solicitous $\alpha=0.70$; distracting $\alpha=0.58$ ). We did not include the distracting spouse responses subscale in the analyses below because of low reliability in the spouse subscale.

2.2.2. Sickness impact profile (SIP-Patient Version, Bergner et al., 1981; SIPSpouse Version, Romano et al., 1989)—The SIP is a measure of disability and functional impairment that has good convergent and discriminant validity and excellent inter-item and test-retest reliabilities (Bergner et al., 1981; Kerns and Jacob, 1992). The spouse version is also psychometrically sound (Romano et al., 1989). Participants were instructed to identify the presence of behaviors that characterize the patient on the day of assessment. Each item is given a weight determined by Bergner et al. (1981) indicating the degree to which the behavior affects daily life and then items within each subscale are summed. The following SIP subscales were used in the current study: physical disability (45 items; i.e. disability in ambulation, body care and movement, mobility), psychosocial disability (48 items; i.e. social interaction, communication, alertness, emotion), and the independent scales of recreation and pastime (8 items), household management (10 items), and work behaviors (8 items). Two other independent scales, eating and sleep/rest, were not used because of poor inter-item reliabilities. The inter-item reliabilities of the physical disability subscales for patients and spouses were excellent ( $\alpha=0.87$ and 0.81 , respectively). Similarly, inter-item reliabilities for patients and spouses on psychosocial disability were excellent ( $\alpha=0.92$ and 0.89 , respectively). The interitem reliabilities for the independent subscales ranged from 0.63 to 0.82 for patients and from 0.65 to 0.85 for spouses.

2.2.3. Structured clinical interview for the DSM-IV (SCID; First et al., 1995)—The SCID is a valid diagnostic assessment instrument based on the Diagnostic and Statistical Manual for Mental Disorders-IV (DSM-IV; APA, 1994). The SCID was administered to assess current depressive disorders (i.e. major depressive disorder, dysthymia, and minor depressive disorder) in the patients. These disorders are characterized by several clinically significant symptoms including depressed mood, appetite problems, sleep disturbance, fatigue, hopelessness, and difficulty concentrating or making decisions for at least 1 month (e.g. major and minor depression) and sometimes for several years (e.g. dysthymia). SCID interviewers participated in a 6-week training workshop conducted by the first author. The workshop included reviewing SCID user's manuals, SCID training videotapes and the accompanying video manual, and conducting practice interviews until reliability was achieved. Each interviewer passed a proficiency interview with the first author before interviewing participants. For the current study, inter-rater reliability was excellent $(\kappa=0.94)$. The prevalence of current depressive disorders was $29.1 \%(n=32)$ in this sample, slightly lower than the prevalence rate of major depression in other chronic pain samples (30-54\%; Romano and Turner, 1985). 


\subsubsection{Mood and anxiety symptom questionnaire (MASQ; Watson and Clark,} 1991) - The SCID was not administered to spouses in the current study. Therefore, the anhedonic depression subscale (22 items) of the MASQ assessed depressive symptoms in spouses. Spouses used a 5-point Likert-type scale ( $1=$ not at all; $5=$ extremely) to identify the extent to which they experienced each symptom in the past week. Given the research demonstrating that depression is not independent within couples (e.g. Hippisley-Cox et al., 2002), it is possible that incongruence is primarily due to depression and perceptual distortions in the spouses. Therefore, this measure was used to control for the possibility that depression in the spouses affected couples' incongruence. An advantage of this subscale is that it measures symptoms specific to depression (e.g. loss of interest, anhedonia) rather than diffuse distress or anxiety symptoms that are often assessed by other checklists. The MASQ has good convergent and discriminant validity, reliability, and a stable factor structure (Geisser et al., 2003; Watson et al., 1995a,b). In the current sample, the anhedonia subscale had excellent inter-item reliability (Anhedonia-spouse, $\alpha=0.95$ ) (Cano et al., 2004).

\subsection{Procedure}

After receiving institutional review board approval, participants were recruited from a university-based pain clinic through fliers posted in the waiting room, psychologists and physicians working with the patients, and letters and phone calls to active patients after obtaining institutional review board approval. Eligible participants were at least 21 years old, married to a spouse who was also interested in participating in the study, reported chronic musculoskeletal pain, and denied terminal illness. After completing consent forms and surveys, patients were interviewed about their pain and were administered the mood module of the SCID. Couples were paid upon completion of the study. While 214 patients expressed interest in the study initially, 110 couples completed the study. The vast majority of patients who showed initial interest in participating did not provide reasons for their lack of study completion (i.e. they did not attend their appointments; did not return phone calls). Some patients stated that they were no longer interested $(n=50)$, were too busy to participate $(n=13)$, were frustrated by pain care $(n=7)$, or their spouses did not want to participate $(n=4)$. More detailed information from these non-completers or from persons who never demonstrated initial interest in the study were not collected. In a previous report involving the same patients but not their spouses (Cano et al., 2004) found that the patients in the current study did not differ from other married patients in the same clinic on ethnic or gender composition, pain duration, or educational attainment. However, our sample was significantly older than married patients from the clinic sample as a whole. Demographic data on the spouses of patients who did not participate were unavailable.

\section{Results}

\subsection{Data analysis plan}

One spouse did not complete the MASQ so the following analyses were performed on 109 couples. To test the hypotheses that patients would report more disability and pain than their spouses, correlated (i.e. paired) samples $t$-tests were performed. Paired samples $t$-tests take into account the non-independence of each spouse's rating within a couple. These initial analyses were undertaken because so little research examined simple congruence in musculoskeletal samples. To examine whether mood disorder and gender of the patient were related to patientspouse incongruence on disability, pain, and spouse responses to pain, we conducted 2 (patient versus spouse) $\times 2$ (depressive disorder) $\times 2$ (gender) correlated samples analyses of covariance (ANCOVA). The correlated samples ANCOVA is also known as within-subjects or repeated measures analysis and was used because the couple was the unit of analysis (i.e. spouses are nested within couples). When appropriate, post hoc analyses were performed to determine the nature of the ANCOVA findings. Paired samples $t$-tests were used to test incongruence within 
couples whereas independent samples $t$-tests were used to test differences between couples. A more conservative significance level of $P<0.01$ was chosen for these comparisons. Although multilevel modeling is another analytic approach that can be used in the analysis of dyadic data, there are some problems in applying this technique to the current data. Some work indicates that random effects and their standard errors can be seriously biased when the level 2 variable consists of only two observations (e.g. longitudinal data with only two assessments, groups with only two members; Newsom and Nishishiba, 2002). In other words, using multilevel modeling in the current study might result in variance estimates for the random effects (i.e. couple and individual spouse effects) that are unstable and biased. Therefore, $t$ tests and ANOVAs were chosen to analyze the current data.

Spouse anhedonia was included as a covariate in the correlated samples ANCOVAs when it was associated with either patient or spouse ratings of pain, disability, and spouse responses at the $P<0.05$ level. Therefore, it was considered a covariate in analyses of physical disability, psychosocial disability, household management disability, recreation and pastime disability, pain severity, and negative spouse responses to pain. Spouse anhedonia was not included in the ANOVAs involving work disability and solicitous spouse responses because it was not significantly correlated with these variables.

\subsection{Correlated samples t-tests}

Consistent with findings in the cancer pain literature (e.g. Miaskowski et al., 1997; Yeager et al., 1995), spouses reported that the patients were experiencing more pain severity than the patients reported, $P<0.001$ (see Table 2). Patients reported that they were more disabled in terms of physical disability, psychosocial disability, and recreation and pastime than their spouses rated them, $P<0.01$. Recall that patients and spouses rated the patients' pain and disability and the spouses' responses to the pain patient. There were no significant differences on work disability, household management, or spouse responses to pain. The $d$ s indicate that differences on pain severity and disability measures were in the small to medium effect range (Cohen, 1988).

\subsection{The interaction of depression}

The ANCOVA showed that depressive disorder in the patient interacted with spouses' ratings, $F(1,104)=5.39, P<0.03$. Although depressed and non-depressed patients reported significantly more physical disability than their spouses, $P<0.01$, couples in which patients were diagnosed with a current depressive disorder were characterized by greater disagreement on the patients' physical disability than couples in which the patients were not depressed. Fig. 1 displays the mean and standard errors. Independent samples $t$-tests also showed that depressed patients reported significantly more physical disability than non-depressed patients, $P<$ 0.0001 , and that the spouses of depressed and non-depressed patients differed significantly, $P<0.01$.

The correlated samples ANCOVA also showed a significant depressive disorder effect on psychosocial disability, $F(1,104)=9.28, P<0.01$ (see Fig. 2). Depressed patients reported significantly more psychosocial disability than their spouses, $P<0.001$, whereas only a trend existed for non-depressed patients and their spouses, $P<0.03$. In addition, independent samples $t$-tests showed that depressed patients reported more psychosocial disability than nondepressed patients and the spouses of depressed patients reported more psychosocial disability than the spouses of non-depressed patients, $P<0.0001$. No other effects were significant. One might argue that psychosocial disability and depressive disorder are essentially the same construct. Although the correlations between depressive disorder and psychosocial disability were large according to Cohen (1988) (patient report: $r=0.59, P<0.0001$; spouse report: $r=$ 
$0.47, P<0.0001$ ), the sizes of these effects also indicate that psychosocial disability and depressive disorder do not overlap entirely and are measuring different constructs.

Although there were no significant differences between patients and their spouses on spouse responses to pain, the correlated samples ANCOVAs were run to examine possible interactions with depression and gender. Results showed a significant effect for depressive disorder on negative spouse responses to pain, $F(1,104)=5.56, P<0.03$. Paired samples $t$-tests revealed that spouses of non-depressed patients reported of engaging in slightly more negative spouse responses $(M=1.71, \mathrm{SE}=0.55)$ than reported by the patients $(M=1.49, \mathrm{SE}=0.66), P<0.05$. No significant differences were apparent between depressed patients $(M=2.24, \mathrm{SE}=1.15)$ and their spouses $(M=1.88, \mathrm{SE}=0.97)$. Independent samples $t$-tests showed that depressed patients reported more negative spouse responses than non-depressed patients, $P<0.02$, whereas spouses of depressed and non-depressed patients did not differ significantly, $P>0.45$.

\subsection{The interaction of gender}

A significant gender effect emerged for physical disability, $F(1,104)=4.96, P<0.03$ (Fig. 3 ). Paired samples $t$-tests were conducted separately for female and male patient couples to determine the nature of this effect. These analyses showed that female patients reported significantly more physical disability than their husbands, $P<0.001$; whereas no significant difference was found in male patient couples, $P>0.30$. That is, female patients reported that they were more disabled than their husbands rated them but male patients and their wives did not rate the men's disability differently. Independent samples $t$-tests showed that female patients did not differ from male patients nor did the husbands and wives of patients differ on reports of physical disability, $P>0.20$. The three-way interaction between couples' ratings of physical disability, depressive disorder, and gender were not significant.

A trend for gender was also found for solicitous spouse responses, $F(1,106)=3.92, P=0.05$. Female patients and their husbands reported similarly on the levels of the husbands' solicitous responses (female patients: $M=3.38, \mathrm{SE}=1.10$; husbands: $M=3.34, \mathrm{SE}=0.88$ ),$P>0.90$. Male patients reported slightly fewer solicitous wife responses $(M=3.07, \mathrm{SE}=1.18)$ than their wives reported $(M=3.50, \mathrm{SE}=1.02), P<0.04$. Female patients did not differ from male patients nor did female spouses differ from male spouses on solicitous spouse responses, $P>$ 0.20 . There were no significant effects of patient depression or patient gender on household management, recreation pastime, work disability, or pain severity.

\section{Discussion}

An aim of the current study was to determine the degree to which chronic pain patients and their spouses were congruent on ratings of the patients' pain experience. As expected, spouses rated pain severity as more severe. This finding is consistent with previous research in cancer pain populations (Clipp and George, 1992; Miaskowski et al., 1997; Yeager et al., 1995).

Similar findings were expected for disability. However, patients rated their disability as more severe than their spouses rated them. Another study found that some spouses overestimated whereas others underestimated the disability reported by RA patients (Riemsma et al., 2000) but a cancer study reported better agreement between spouses on some measures of functional impairment (e.g. ability to dress independently; Clipp and George, 1992). Perhaps disability incongruence is sensitive to pain diagnosis and the disability measure used.

Our results partially support the notion that spouses may engage in defensive distancing (Pyszcynski et al., 1995). Spouses may overestimate the pain severity because verbalizations of pain are difficult to avoid. These verbalizations may heighten spouses' distress and therefore their ratings of pain. In turn, spouses may distance themselves from observing the full extent to which the pain problem is disabling the patient. These findings suggest that relying on only 
one observer may not provide enough information to make informed judgments about illness impact.

We also found that the degree to which spouses are congruent may depend on patient depression and gender. Support was found for the hypothesis that patients and their spouses would be more incongruent on physical and psychosocial disability when the patient was diagnosed with a depressive disorder. This finding provides further evidence for a link between psychological distress and pain and disability (Brown, 1990; Cano et al., 2000, 2004; Kerns et al., 1990; Romano and Turner, 1985; Schiaffino and Revenson, 1995; Schwartz et al., 1991). Depressed patients might selectively attend to negative stimuli (Blaney, 1986; Bradley et al., 1995; Siegle et al., 2002) including pain-related information. Spouses of depressed patients may also engage in greater defensive distancing (Pyszcynski et al., 1995) to avoid uneasiness elicited by the physical and psychological illnesses. Furthermore, depressive social withdrawal and defensive distancing may increase the difficulty with which patients can communicate, directly or indirectly, their disability experience to their spouses. If disability is considered a way for patients to indirectly communicate about their pain, these results suggest that patients may be more effective communicators when they are not depressed. This finding fits well with Joiner and Coyne's (1999) interactional model of depression in which depression can alienate the depressed person from loved ones. Alternatively, depressed patients and their spouses may be attending to different information that results in incongruence. Perhaps depressed patients attend to activity limitation that interferes with all activity whereas their spouses attend to pain behaviors and activity limitation that interferes with joint activities or family roles. In any case, clinicians should be aware that careful assessment of both spouses is needed when the patient is depressed.

It was expected that patient depression would also interact with patient-spouse ratings of other forms of disability or pain severity. However, this was not the case. Perhaps the reliabilities of the other forms of disability were not high enough for effects to be detected. In terms of pain severity, which may serve a more direct and obvious interpersonal communication function than disability, depression may not be important in congruence. Spouses may assume that patients are in a great deal of pain regardless of patient depression or social withdrawal. They may also selectively attend to information supporting this assumption (e.g. seeing the patient take medication) but distance themselves from more threatening information (e.g. acknowledging the impact of pain on daily life).

Gender affected the relationship between patient and spouse ratings of physical disability. As expected, patients and their spouses were more incongruent when the patient was female. This finding could be a result of female patients exaggerating or catastrophizing about the pain more than male patients (Keefe et al., 2000; Wise et al., 2002). In addition, person perception research suggests that husbands of female patients may be inaccurate perceivers of the disability (Ickes et al., 2000). Perhaps men are more inaccurate because they are more likely to engage in defensive distancing (Whitehead and Smith, 2002). An experimental study may show that accurate person perception is an artifact of motivation rather than skill level as suggested by Ickes et al. (2000). Although we also expected female patient couples to be more incongruent on pain as in Beaupre et al. (1997) and other forms of disability, this was not the case. Both male and female spouses may be affected by the same biases in rating pain severity and other forms of disability. Research may identify differences in the types of pain information to which husbands and wives attend (e.g. pain behaviors, effect of pain on sexual functioning) or that rating methods affect the degree of incongruence.

Unexpectedly, there were no significant patient-spouse disagreements on spouse responses to pain. However, non-depressed patients reported that their spouses engaged in slightly fewer negative spouse responses than reported by the spouses. These results were expected based on 
social psychological research showing that spouses tend to perceive their partners' behaviors through a relationship-enhancing lens (Sénecal et al., 2003). Non-depressed patients may find it easier to disregard negative spouse responses and may be more resilient to interpersonal stress brought on by the pain problem. Conversely, following interpersonal theories of depression (Hammen, 1991; Joiner and Coyne, 1999), the presence of depression may generate relationship stress that is noticeable to both spouses (i.e. negative spouse responses).

Gender also interacted with reports of spouse responses. Female patient couples exhibited relative congruence whereas male patients reported that their wives were slightly less solicitous. While we expected the former, the latter finding ran counter to our expectation that wives of male patients would be more motivated to portray themselves as supportive. Wives may demonstrate that they are in agreement with male patients on their level of pain and disability but male patients might not find this particularly validating. Perhaps male patients expect that their wives should fulfill a traditionally feminine role in caring for ill family members (e.g. reassurance, support). These results should be interpreted with some caution because they failed to reach significance. Nevertheless, the spouse response findings reflect social support research suggesting that perceived and enacted support are not necessarily equivalent (e.g. Barrera, 1986; Lakey and Drew, 1997). Clinicians are encouraged to ask each partner about the spouse's reactions to the pain to learn more about the interpersonal dynamic that may impact incongruence.

To date, researchers have suggested that incongruence between patients and caregivers leads to mood problems in patients and sometimes, caregivers (Cremeans-Smith et al., 2003; Miaskowski et al., 1997; Riemsma et al., 2000; Yeager et al., 1995). It is also possible that the mood disturbance affects the extent to which patients and caregivers are incongruent. Longitudinal studies may demonstrate that depression leads to larger patient-spouse discrepancies over time or vice versa. The patterns of relationships might also depend on pain diagnosis (i.e. cancer, RA, musculoskeletal). Our findings may be limited to self-selected samples of chronic musculoskeletal pain patients for whom the pain is present daily, with lower likelihoods of pain-free periods as in RA and of death as in cancer. Other research may answer the question of whether caregiver gender and relationship type are important. Research incorporating depressive disorders or defensive distancing in spouses might improve our understanding of the interpersonal context in which pain occurs. For instance, researchers may find that defensive distancing is beneficial when spouses encourage healthy activity levels but detrimental when spouses encourage patients to overexert themselves.

Previous research has highlighted the importance of patients' perceptions of the social context in relating to psychological distress (Cano et al., 2000, 2004; Flor et al., 1987; Kerns et al., 1990; Nicassio and Radojevic, 1993; Romano et al., 1997) and activity level (Ahern et al., 1985; Flor et al., 1987; Schwartz et al., 1994). The results of the current study go one step further to suggest that obtaining reports from the patient alone may not provide complete information about the social context in which the pain and disability occur. Furthermore, differences in the way depression and gender might affect various types of interaction or information processing between chronic pain patients and their spouses suggest that an interpersonal approach to the study and treatment of pain is necessary. For instance, whereas depression may result in more difficulty in communicating information that is less directly interpersonal (i.e. disability), it may enhance the accurate perception of direct spouse communication such as negative spouse responses. Recent advances in couples therapy suggest that greater emotional acceptance and empathy can improve the relationship (Christensen et al., 1995; Jacobson et al., 2000). Future research might indicate that one aim of treatment is to enhance the couple's empathy and skill in behavior assessment so as to improve pain treatment compliance and overall relationship well-being. 


\section{Acknowledgements}

The authors wish to thank Mazy Gillis, Wanda Heinz, and Heather Foran for their help in conducting this study. This research was supported by grants R03 MH61569-01 and K01 MH66975 awarded to the first author.

\section{References}

Ahern DK, Adams AE, Follick MJ. Emotional and marital disturbance in spouses of chronic low back pain patients. Clin J Pain 1985;1:69-74.

American Psychiatric Association. The Diagnostic and Statistical Manual of Mental Disorders. Vol. 4th ed. Washington, DC: Author; 1994.

Barrera M Jr. Distinctions between social support concepts, measures and models. Am J Community Psychol 1986;14:413-455.

Beaupre P, Keefe FJ, Lester N, Affleck G, Fredrickson B, Caldwell S. A computer-assisted observational method for assessing spouses' ratings of osteoarthritis patients' pain. Psychol Health Med 1997;2:99_ 108.

Bergner M, Bobbitt RA, Carter WB, Gilson BS. The Sickness Impact Profile: development and final revision of a health status measure. Med Care 1981;19:787-805. [PubMed: 7278416]

Bernieri FJ, Zuckerman M, Koestner R, Rosenthal R. Measuring person perception accuracy: another look at self-other agreement. Pers Soc Psychol Bull 1994;20:367-378.

Blaney PH. Affect and memory: a review. Psychol Bull 1986;99:229-246. [PubMed: 3515383]

Bradley BP, Mogg K, Williams R. Implicit and explicit memory for emotion-congruent information in clinical depression and anxiety. Behav Res Ther 1995;33:755-770. [PubMed: 7677713]

Brown GK. A causal analysis of chronic pain and depression. J Abnorm Psychol 1990;99:127-137. [PubMed: 2348006]

Cano A, Weisberg J, Gallagher M. Marital satisfaction and pain severity mediate the association between negative spouse responses to pain and depressive symptoms in a chronic pain patient sample. Pain Med 2000;1:35-43. [PubMed: 15101962]

Cano A, Gillis M, Heinz W, Geisser M, Foran H. Marital functioning, chronic pain, and psychological distress. Pain 2004;107(1-2):99-106. [PubMed: 14715395]

Christensen, A.; Jacobson, NS.; Babcock, JC. Integrative behavioral couple therapy. In: Jacobson, NS.; Gurman, AS., editors. Clinical handbook of couple therapy. New York: Guilford Press; 1995. p. 31-90.

Clipp EC, George LK. Patients with cancer and their spouse caregivers. Pain 1992;69:1074-1079.

Cohen, J. Statistical power analysis for the behavioral sciences. Vol. 2nd ed. Hillsdale, NJ: Lawrence Erlbaum Associates; 1988.

Cremeans-Smith JK, Parris Stephens MA, Franks MM, Martire LM, Franks MM, Druley JA, Wojno WC. Spouses' and physicians' perceptions of pain severity in older women with osteoarthritis: dyadic agreement and patients' well-being. Pain 2003;106:27-34. [PubMed: 14581107]

First, MB.; Spitzer, RL.; Gibbon, M.; Williams, JBW. Structured clinical interview for axis I DSM-IV disorders (SCID). Washington, DC: American Psychiatric Association; 1995.

Flor H, Kerns R, Turk DC. The role of spouse reinforcement, perceived pain, and activity levels of chronic pain patients. J Psychosom Res 1987;31:251-259. [PubMed: 3585827]

Fordyce, WE. Behavioral methods for chronic pain and illness. St Louis, MO: CV Mosby; 1976.

Geisser, ME.; Cano, A.; Foran, H. Psychometric properties of the mood and anxiety symptom questionnaire in chronic pain patients. Ann Arbor, MI: University of Michigan; 2003. Unpublished manuscript.

Hall JA. Gender effects in decoding nonverbal cues. Psychol Bull 1978;85:845-857.

Hammen CL. The generation of stress in the course of unipolar depression. J Abnorm Psychol 1991;100:555-561. [PubMed: 1757669]

Hippisley-Cox J, Coupland C, Pringle M, Crown N, Hammersley V. Married couples' risk of same disease: cross-sectional study. Br Med J 2002;325:636-640. [PubMed: 12242177] 
Ickes W, Gesn PR, Graham T. Gender differences in empathic accuracy: differential ability or differential motivation? Pers Rel 2000;7:95-109.

Jacobson NS, Christensen A, Prince SE, Cordova J, Eldridge K. Integrative behavioral couple therapy: an acceptance-based, promising new treatment for couple discord. J Consult Clin Psychol 2000;68:351-355. [PubMed: 10780137]

Joiner, T.; Coyne, JC. The interactional nature of depression. Washington, DC: American Psychological Association; 1999.

Keefe FJ, Lefebvre JC, Egert JR, Affleck G, Sullivan MJ, Caldwell DS. The relationship of gender to pain, pain behavior, and disability in osteoarthritis patients: the role of catastrophizing. Pain 2000;87:325-334. [PubMed: 10963912]

Kerns, RD.; Jacob, MC. Assessment of the psychosocial context of the experience of chronic pain. In: Turk, DC.; Melzack, R., editors. Handbook of pain assessment. New York: Guilford Press; 1992. p. 235-253.

Kerns RD, Rosenberg R. Pain-relevant responses from significant others: development of a significantother version of the MPI scales. Pain 1995;61:245-249. [PubMed: 7659434]

Kerns RD, Turk DC, Rudy TE. The West Haven-Yale multidimensional pain inventory. Pain 1985;23:345-356. [PubMed: 4088697]

Kerns RD, Haythornthwaite J, Southwick S, Giller EL Jr. The role of marital interaction in chronic pain and depressive symptom severity. J Psychosom Res 1990;34:401-408. [PubMed: 2142961]

Lakey, B.; Drew, J. A social-cognitive perspective of social support. In: Pierce, GR.; Lakey, B.; Sarason, IG.; Sarason, BR., editors. Sourcebook of social support and personality. New York: Plenum Press; 1997. p. 107-140.

Miaskowski C, Zimmer EF, Barrett KM, Dibble SL, Wallhagen M. Differences in patients' and family caregivers' perceptions of the pain experience influence patient and caregiver outcomes. Pain 1997;72:217-226. [PubMed: 9272806]

Newsom, JT.; Nishishiba, M. Nonconvergence and sample bias in hierarchical linear modeling of dyadic data. Portland, OR: Portland State University; Unpublished manuscript.

Nicassio PM, Radojevic V. Models of family functioning and their contribution to patient outcomes in chronic pain. Motiv Emot 1993;17:295-316.

Pyszcynski T, Greenberg J, Solomon S, Cather C, Gat I, Sideris J. Defensive distancing from victims of serious illness: the role of delay. Pers Soc Psychol Bull 1995;21:13-20.

Riemsma RP, Taal E, Rasker JJ. Perceptions about perceived functional disabilities and pain of people with rheumatoid arthritis: differences between patients and their spouses and correlates with wellbeing. Arthritis Care Res 2000;13:255-261. [PubMed: 14635293]

Romano JM, Turner JA. Chronic pain and depression: does the evidence support a relationship? Psychol Bull 1985;97:18-34. [PubMed: 3983297]

Romano JM, Turner JA, Clancy SL. Sex differences in the relationship of pain patient dysfunction to spouse adjustment. Pain 1989;39:289-295. [PubMed: 2616180]

Romano JM, Turner JA, Jensen MP. The family environment in chronic pain patients: comparison to controls and relationship to patient functioning. J Clin Psychol Med Settings 1997;4:383-395.

Schiaffino KM, Revenson TA. Relative contributions of spousal support and illness appraisals to depressed mood in arthritis patients. Arthritis Care Res 1995;8:80-87. [PubMed: 7794990]

Schwartz L, Slater MA, Birchler GR, Atkinson JH. Depression in spouses of chronic pain patients: the role of patient pain and anger, and marital satisfaction. Pain 1991;44:61-67. [PubMed: 2038490]

Schwartz L, Slater MA, Birchler GR. Interpersonal stress and pain behaviors in patients with chronic pain. J Consult Clin Psychol 1994;62:861-864. [PubMed: 7962892]

Senécal S, Murard N, Hess U. Do you know what I feel? Partners' predictions and judgments of each other's emotional reactions to emotion-eliciting situations. Sex Roles 2003;48:21-37.

Siegle GJ, Ingram RE, Matt GE. Affective interference: an explanation for negative attention biases in dysphoria? Cogn Ther Res 2002;26:73-87.

Turk, DC.; Meichenbaum, D.; Genest, M. Pain and behavioral medicine: a cognitive-behavioral perspective. New York: Guilford Press; 1983. 
Watson, D.; Clark, LA. Mood and anxiety symptom questionnaire. Iowa City, IA: Department of Psychology, University of Iowa; 1991. Unpublished manuscript.

Watson D, Weber K, Assenheimer JS, Clark LA, Strauss ME, McCormick RA. Testing a tripartite model: I. Evaluating the convergent and discriminant validity of anxiety and depression symptoms scales. J Abnorm Psychol 1995a;104:3-14. [PubMed: 7897050]

Watson D, Clark LA, Weber K, Assenheimer JS, Strauss ME, McCormick RA. Testing a tripartite model: II. Exploring the symptom structure of anxiety and depression in student, adult, and patient samples. J Abnorm Psychol 1995b;104:15-25. [PubMed: 7897037]

Whitehead GI, Smith SH. When illnesses or accidents befall others: the role of gender in defensive distancing. Sex Roles 2002;46:393-401.

Wise EA, Price DD, Myers CD, Heft MW, Robinson ME. Gender role expectations of pain: relationship to experimental pain perception. Pain 2002;96:335-342. [PubMed: 11973007]

Yeager KA, Miaskowski C, Dibble SL, Wallhagen M. Differences in pain knowledge and experience in oncology outpatients and their caregivers. Oncol Nurs Forum 1995;22:1235-1241. [PubMed: 8532548] 


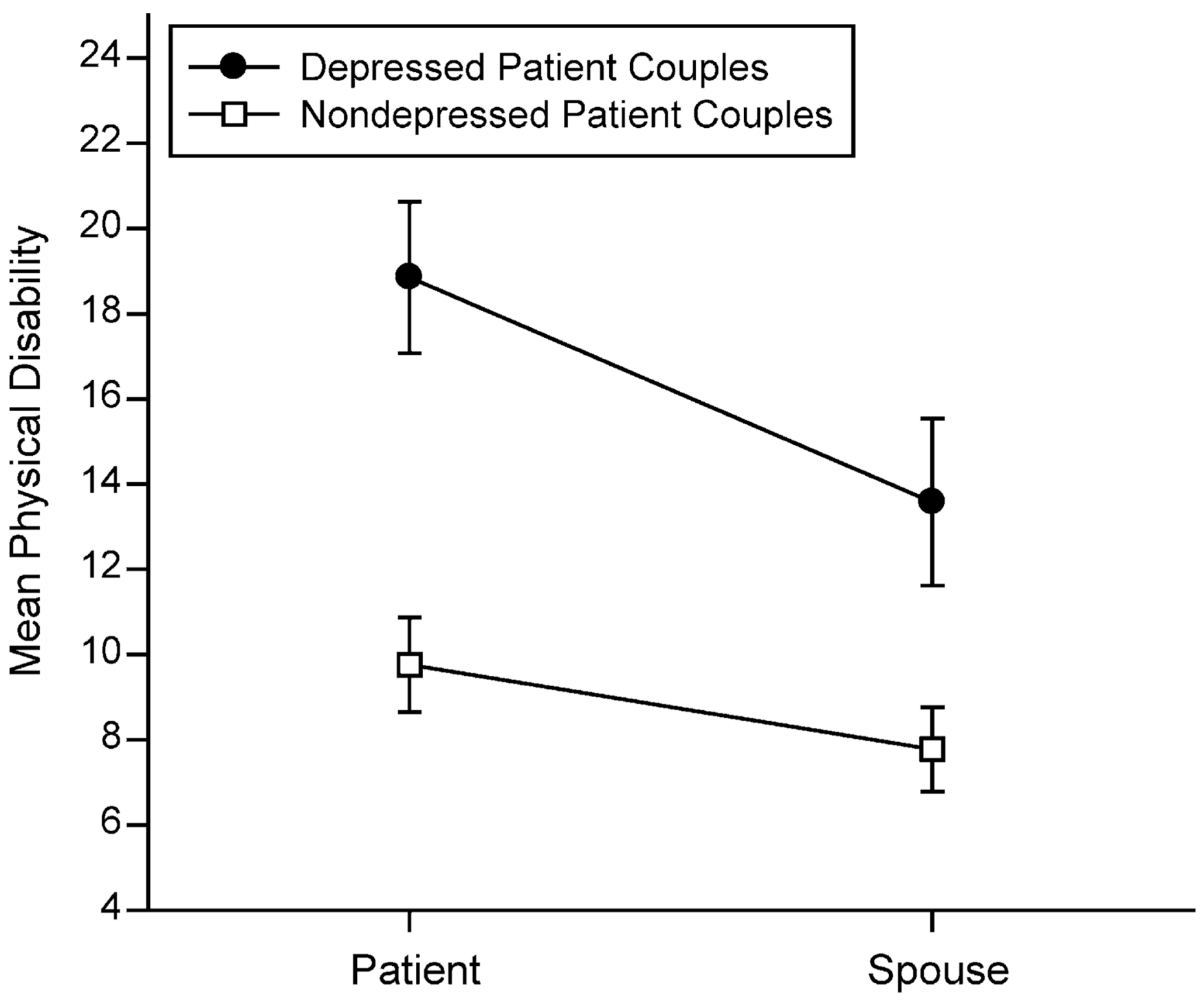

Fig. 1.

Within-couple differences in reporting patient physical disability as a function of patient depression. Means and standard errors are displayed for depressed patients and their spouses as well as for non-depressed patients and their spouses. 


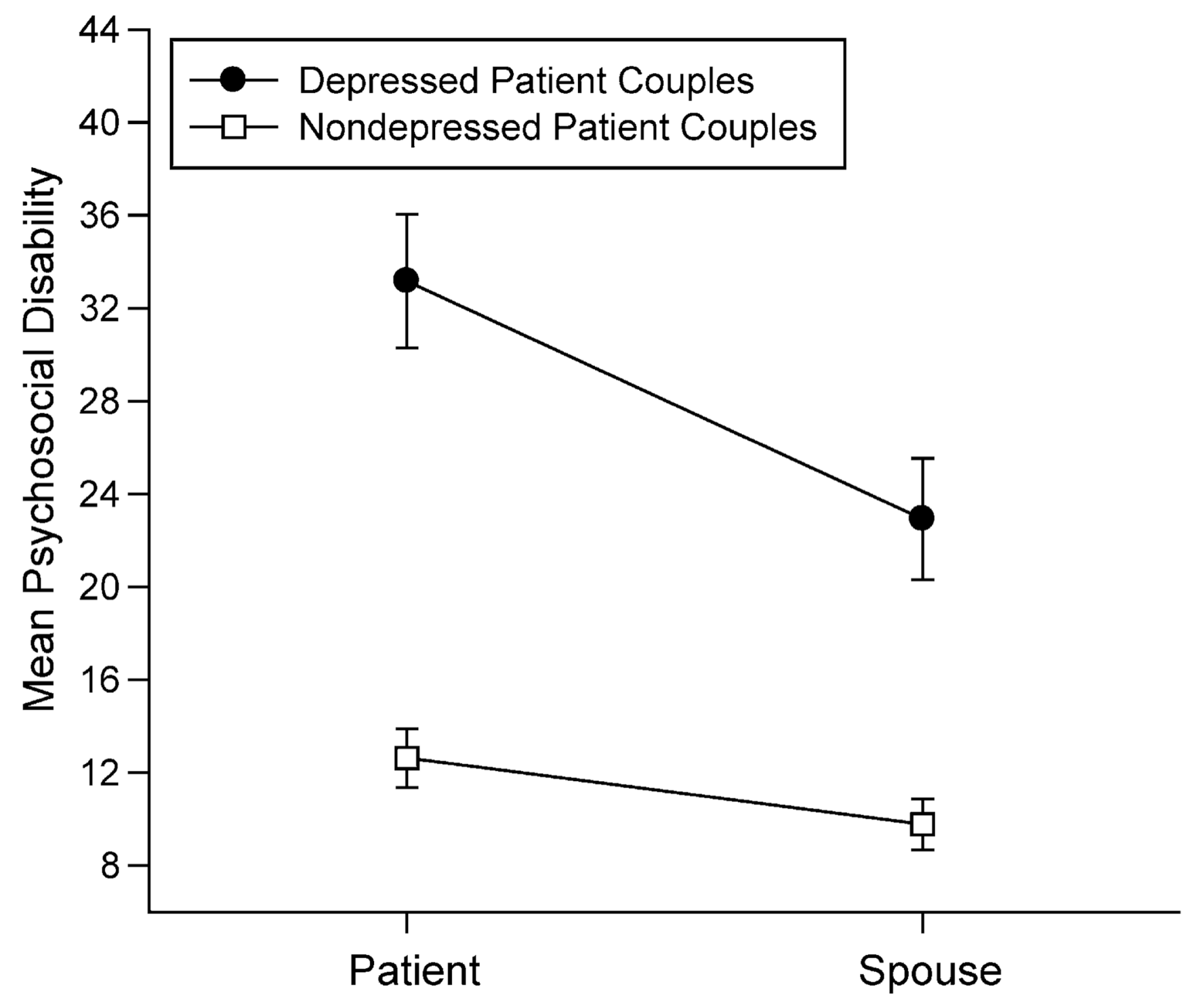

Fig. 2.

Within-couple differences in reporting patient psychosocial disability as a function of patient depression. Means and standard errors are displayed for depressed patients and their spouses as well as for non-depressed patients and their spouses. 


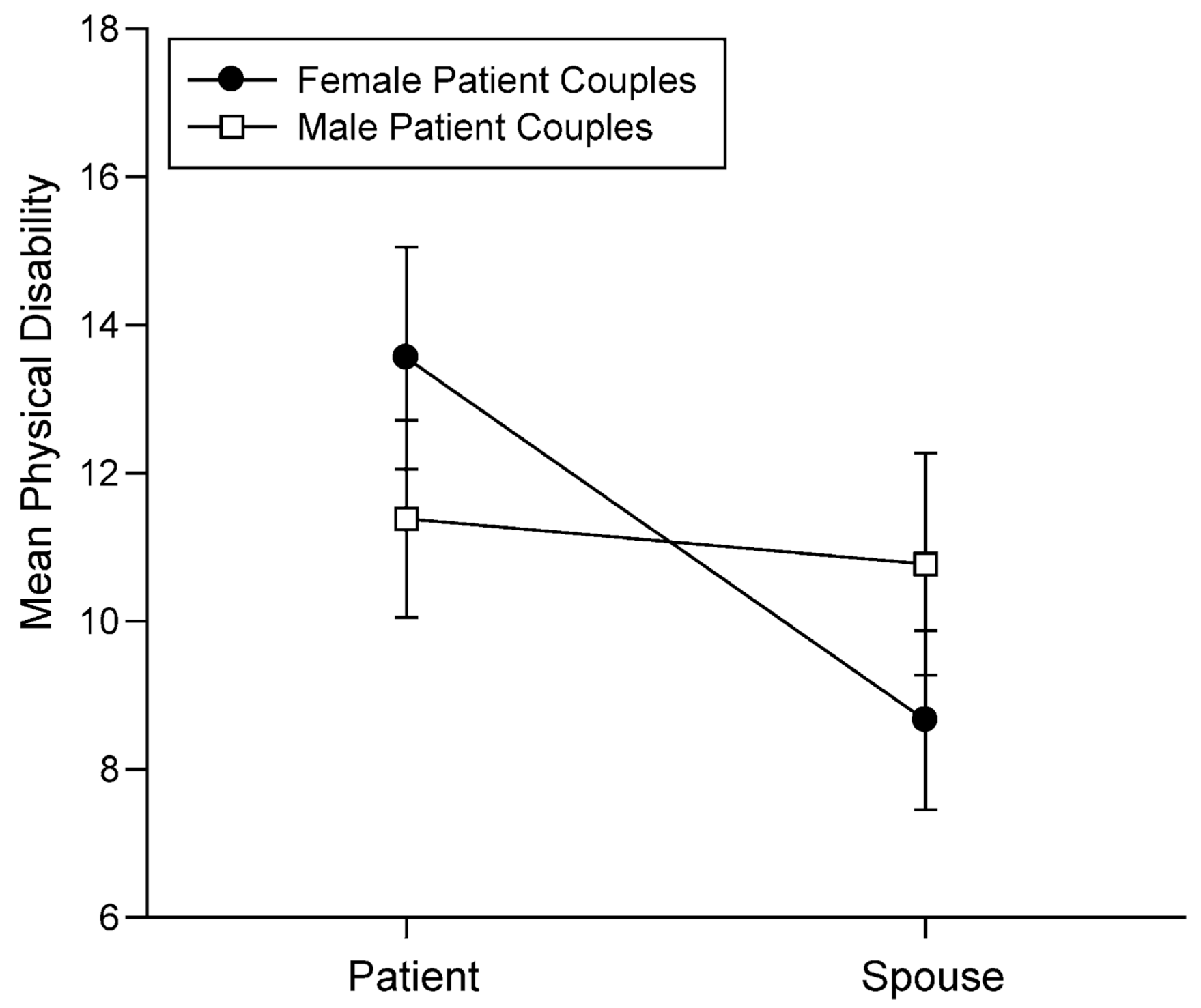

Fig. 3.

Within-couple differences in reporting patient physical disability as a function of patient gender. Means and standard errors are displayed for couples in which the patient is female and for couples in which the patient is male. 
Table 1

Demographic characteristics of participants

\begin{tabular}{|c|c|c|c|c|}
\hline & \multicolumn{2}{|c|}{ Patients } & \multicolumn{2}{|c|}{ Spouses } \\
\hline & M & (SD) & $\mathbf{M}$ & (SD) \\
\hline Age & 46.28 & (10.48) & 45.41 & $(9.31)$ \\
\hline Years education & 14.04 & $(2.80)$ & 14.32 & $(2.80)$ \\
\hline Work status ${ }^{a}$ & $\%$ & $(n)$ & $\%$ & $(n)$ \\
\hline At least part-time & 43 & (47) & 75 & $(82)$ \\
\hline Receiving social security & 30 & (33) & 3 & (3) \\
\hline \multicolumn{5}{|l|}{ Or disability benefits } \\
\hline Unemployed & 31 & (34) & 12 & (13) \\
\hline Retired & 9 & (10) & 11 & (12) \\
\hline
\end{tabular}

${ }^{a}$ Percentages do not add up to $100 \%$ because some participants indicated more than one work status. 
Table 2

Paired sample $t$-tests comparing reports of pain severity, disability, and spouse responses within couples

\begin{tabular}{lcccc}
\hline & Patient $\boldsymbol{M}$ (SE) & Spouse $\boldsymbol{M}($ SE) & & $\boldsymbol{t}$ \\
\hline Pain severity & $11.54(0.34)$ & $12.56(0.32)$ & $-3.52^{* *}$ & -0.30 \\
Physical disability & $12.59(1.02)$ & $9.59(0.95)$ & $3.89^{* * *}$ & 0.29 \\
Psychosocial disability & $19.03(1.55)$ & $13.88(1.25)$ & $4.16^{* * *}$ & 0.35 \\
Recreation and pastime & $13.43(.89)$ & $10.96(0.97)$ & $2.67^{*}$ & 0.25 \\
Household management & $16.18(1.18)$ & $13.28(1.15)$ & $2.58^{\dagger}$ & 0.24 \\
Work & $8.49(1.55)$ & $5.06(1.30)$ & $2.47^{\dagger}$ & 0.36 \\
Negative spouse responses & $1.72(0.59)$ & $1.77(0.48)$ & -0.35 & -0.03 \\
Solicitous spouse responses & $3.24(0.81)$ & $3.41(0.66)$ & -1.32 & -0.13 \\
\hline
\end{tabular}

$n=109$ for all analyses with the exception of work. For work, $n=47$ because only those who were currently working could be evaluated on this subscale.

${ }^{\dagger} P<0.02$

* $P<0.01$

${ }^{* *} P<0.001$

${ }^{* * *} P<0.0001$. 